Research Article

\title{
Direct Effect and Spillover Effect of ICT on Electricity Consumption in China: Evidence from a Spatial Panel Analysis
}

\author{
Jianjun $\mathrm{Xu} \mathbb{D}^{1,2}$ and Xiaowei Yang $\mathbb{D}^{3}$ \\ ${ }^{1}$ College of Science \& Technology, Ningbo University, Ningbo 315300, China \\ ${ }^{2}$ School of Economics and Management, Dalian University of Technology, Dalian 116024, China \\ ${ }^{3}$ Business School, Ningbo City College of Vocational Technology, Ningbo 315000, China \\ Correspondence should be addressed to Jianjun Xu; xujianjun@mail.dlut.edu.cn
}

Received 8 December 2020; Revised 30 January 2021; Accepted 22 February 2021; Published 9 March 2021

Academic Editor: Chiara Boccaletti

Copyright (C) 2021 Jianjun $\mathrm{Xu}$ and Xiaowei Yang. This is an open access article distributed under the Creative Commons Attribution License, which permits unrestricted use, distribution, and reproduction in any medium, provided the original work is properly cited.

\begin{abstract}
The extensive use of information and communication technologies (ICT) has facilitated people's lives and promoted the improvement of productivity. In the meantime, ICT has a profound effect on the efficiency of electricity utilization and the demand for electricity. The existing studies consider the direct effect of ICT on electricity consumption (EC) but neglect the spillover effect of ICT on EC and their action channels. Under the assumption of cross-section dependence, this paper introduces spatial modeling techniques to confirm the positive direct effect and negative spillover effect of ICT on EC. The positive direct effects and negative spillover effects of information technology on EC are similar to those of the communication technology, and the absolute value of the former is also greater than the latter. Additionally, the results of meditation effect modeling also confirm that there exists an incomplete mediating effect in the process of the ICT affecting EC through the channels of economic growth and the adjustment of the industrial structure. This study provides freshly empirical evidence for people to better understand the role of ICT in EC and opens fresh insights for policymakers to make corresponding policy adjustments.
\end{abstract}

\section{Introduction}

The pervasive use of information and communication technologies (ICT), such as the Internet and mobile phones, has had a wide impact on people's lives [1]. Many studies have shown that the extensive application of ICT has played an important role in global economic growth, productivity improvement, and energy consumption [2]. Although scholars basically agree that the use of ICT can improve energy efficiency, there are different views on whether ICT can promote energy consumption or energy-saving. Some studies have noted that the application of ICT is beneficial to energy conservation and emission reduction [3, 4]. According to Greenpeace International [5], the use of ICT reduced global $\mathrm{CO}_{2}$ emissions by $2 \%$. The other studies believe that the application of ICT will increase more electricity demand [6,7]. Faucheux and Nicolaï [8] found that a large part of the electricity consumption (EC) in
Europe is related to ICT products and services. International Energy Agency [9] pointed out that, in the past 20 years, the use of ICT has led to an annual increase of about 7\% in EC.

As far as China is concerned, remarkable achievements have been made in the development and application of ICT. According to "the 45th China Statistical Report on Internet Development" issued by China Internet Network Information Centre (CNNIC), as of March 2020, China's Internet users reached 904 million, the Internet penetration rate (Internet users/aggregate population) reached $64.5 \%$, mobile Internet users reached 897 million, and the proportion of Internet users using mobile phones to access the Internet reached $99.3 \%$. Compared with five years ago, the average download rate of mobile broadband increased by about six times, and the level of mobile Internet traffic dropped by more than $90 \%$. "Speed up and fee reduction" project in China promoted a substantial increase in mobile Internet traffic, with an average monthly mobile traffic of $7.2 \mathrm{~GB}, 1.2$ times the global average; 
mobile Internet access traffic consumption reached 55.39 billion GB, a year-on-year increase of $107.3 \%$. There is no doubt that the use of ICT will play a more significant role in China's economic development. Meanwhile, the use of ICT has a profound impact on the demand and supply of electricity. According to the data released by the China Federation of Electricity Enterprises on January 29, 2019, China's total EC in 2018 was 6.84 trillion $\mathrm{kWh}$, an increase of $8.5 \%$ year on year. Among them, in 2018, the EC of China's secondary industry was 4.72 trillion $\mathrm{kWh}$, with a year-on-year growth of $7.2 \%$, and that of the tertiary industry was 1.08 trillion $\mathrm{kWh}$, with a year-on-year growth of $12.7 \%$, especially that of information transmission, software and information technology services, with a year-on-year growth of $23.5 \%$. In order to alleviate the increasing pressure of electricity demand brought by the development of ICT, we should correctly coordinate the relationship between the development of ICT and EC demand, and the premise of coordinating the relationship is to correctly understand the complex relationship between them.

At present, some achievements have confirmed the demand growth effect of ITC on EC [10-16]. Unfortunately, the existing empirical literature on the relationship between ICT and EC does not consider the spatial dependence of EC. Because these methods being used in existing studies assume that the cross-section elements are independent [14-16], the existing studies only consider the direct impact of ICT on EC in decision-making units, but neglect the indirect effect of EC caused by the spillover of ICT in spatial neighboring units, which may underestimate or overestimate the comprehensive impact of ICT on EC. In addition, the existing studies, such as Shahbaz et al. [12], Saidi et al. [14], and Afzal et al. [16], regarded ICT and economic growth as independent variables affecting EC and did not reveal the mediation role of economic growth in the process of ICT promoting EC. In this study, we take China for example, consider the cross-section dependence of EC variables, and introduce the spatial modeling techniques and the mediation effect model to conduct an empirical test. Our focus is concentrated on the following aspects: what role does ICT play in China's EC? Is there a spatial spillover effect of the ICT on EC? Is there a significant heterogeneity effect of the information technology and the communication technology on EC? Are economic growth and the adjustment of industrial structure the action channels of ICT affecting electricity consumption?

This paper provides freshly empirical evidence for people to better understand the direct effect and indirect effect of ICT affecting EC and their action channels and opens fresh insights for policymakers to make corresponding policy adjustments. The contribution of this paper lies in (1) the prevailing spatial panel modeling techniques are adopted to analyze the relationship between ICT and EC in China. This study not only confirms the direct effect of ITC on EC but also take into account the role of the spillover effect of ITC on EC in China; (2) the analysis of mediation effect model demonstrates that there exists an incomplete mediating effect when ICT effect on EC through the channels of economic growth and the adjustment of the industry structure.

The rest of the study is organized as follows. Section 2 provides a literature review of ICT and EC. Section 3 presents the model and method. Section 4 elaborates on the variables and data. Section 5 elaborates on the empirical results. Section 6 presents conclusions and discussion.

\section{Literature Review}

2.1. Empirical Analyses on the Direct Relationship between ICT and EC. Some researchers pay attention to the effect of ITC on EC, considering not only the contribution of ITC for the growth of the EC but also the electricity-saving capacity of ICT. For example, Cho et al. [17] utilized the logistic model to study the effect of ICT investment, electricity price, and oil price on industrial EC in South Korea. Their empirical analysis shows that ICT investment in manufacturing industries with EC could promote the transformation of input factor substitution from labor-intensive to electricity-intensive. In addition, the results show that investment of ICT in certain manufacturing sectors helps to reduce EC, while investment of ICT in services and most manufacturing sectors increases EC. Sadorsky [6] investigated the effect of ICT on EC in emerging economies. His empirical results of the dynamic panel model showed that there was a positive and statistically significant relationship between ICT and EC.

Schlomann et al. [10] analyzed the net effect of ICT on future EC in Germany. They found that there was great potential for technological progress in reducing the EC of ICT equipment. Afzal and Gow [7] studied the effect of ICT on EC in the next 11 emerging economies during 1990-2014, and their results showed that there was a significant positive correlation between ICT and EC. Kishita et al. [18] constructed an electricity demand model for the telecommunications industry and used scenario planning methods to analyze changes in EC in the telecommunications industry and the possibility of electricity-saving. Their results showed that improving energy efficiency equipment and mobile communication equipment for Internet Protocol (IP) communications were the most effective measures to reduce electricity demand. With quarterly data from 1993q1 to 2014q4, Faisal et al. [15] used the ARDL approach to confirm that there was a U-shaped relationship between Internet use and EC.

However, the existing literature only takes into account the direct effect of ICT on EC, but neglects the spatial the spillover effect of ICT on EC. In this study, we consider the cross-section dependence of variables and use the spatial econometric method to calculate the direct effect and the spillover effect of ITC on EC.

2.2. The Channel of ICT Influencing EC. ICT not only has a direct effect on EC but also indirectly affects the final EC through different path of the mediation channels. One of the important paths may be economic development, including economic growth and the adjustment of the industrial structure. Existing empirical literature, whether based on 
time series research $[11,18]$ or based on panel data modeling [19-25], had proved the positive role of ICT in economic development. Moreover, Cardona et al. [26] reviewed 150 studies and found that most of them confirmed the significant positive effect of ICT on productivity growth. $\mathrm{Vu}$ et al. [27] integrated 208 papers, and most of the research conclusions indicated that ICT had a positive impact on economic growth.

Meanwhile, a large number of documents also confirmed that economic development has increased the demand for electricity energy. Whether based on time series analysis [28-34] or panel data analysis [35-39], most of the empirical results showed that there was a cointegration relationship between economic growth and EC, and there was a Granger causality relationship between economic growth and EC.

Furthermore, some literature also discussed the connection between ICT, economic growth, and EC in a unified framework. For example, Salahuddin and Alam [11], with the annual data from 1985 to 2012, used the ARDL boundary cointegration test method to confirm that the use of the Internet and economic growth stimulated the EC in Australia. Based on the data of the United Arab Emirates from 1975 to 2011, Shahbaz et al. [12] applied the Bayer-Hanck cointegration method to confirm that ICT and revenue growth increased electricity demand, but electricity price reduced electricity demand, and the relationship between ICT and EC was inverted U-shaped. With panel data of OECD from 1985 to 2012, Salahuddin and Alam [19] used a panel cointegration test and mixed mean group regression technology to analyze the relationship among ICT, economic development, and EC. The results show that the use of ICT and economic growth stimulates EC. Combined with the dynamic panel data model of 67 countries from 1990 to 2012, Saidi et al. [14] investigated the impact of ICT and economic growth on EC. Their results demonstrated that the impact of ICT on EC was significantly positive, and economic growth had a positive statistically significant impact on EC. Based on the analysis of the dynamic panel data model from 1990 to 2014, Afzal et al. [16] analyzed the impact of ICT and economic growth on EC in BRICs, and the results showed that ICT and economic growth both had significantly positive effects on EC.

Regrettably, the above literature regarded ICT and economic growth as independent variables affecting EC and did not reveal the mediation role of economic growth in the process of ICT promoting EC. In this study, the mediating effect model is introduced to investigate the mediating role of economic growth and industrial structure adjustment variables in the analysis of the impact of ICT on EC.

\section{Theories and Methods}

3.1. The Effect Mechanism of ICT on Electricity Consumption from a Spatial Perspective. According to Schlomann et al. [10], the impact of ICT on electricity demand may be double.
On the one hand, the impact of local ICT development on EC is mainly reflected in the EC of ICT equipment, and the EC is required for the industrial development using ICT. The growth of ICT equipment will undoubtedly increase the consumption of electric energy and promote the growth of electric energy. In addition, the development of local ICT can also affect EC through mediating variables, e.g., the use of ICT will promote economic growth, which will lead to an increase in the demand for EC, resulting in the so-called rebound effect [40,41].

On the other hand, the use of ICT may improve the efficiency of electric utilization and reduce the EC per unit product $[42,43]$, and the use of ICT may promote the transformation of high electricity consuming industry to low electricity consuming industry, resulting in the decrease of EC [44]. In addition, the development of local ICT can also affect EC through mediating variables, for example, it will promote the optimization and adjustment of economic structure, especially the transformation from high EC industry to low EC industry, which may reduce EC moreover. Finally, whether ICT promotes or hinders EC in different countries or regions remains to be tested.

The forgoing analysis only considers the impact of local ICT on EC but neglects the spillover effect of the ICT in neighboring regions. If different countries or regions are adjacent to each other, not only the development of ICT in local region can affect EC through the abovementioned ways but also the development of ICT in neighboring regions can also affect the local EC by the direct path and mediation path, and this is so-called spillover effect of ICT. Figure 1 shows the effect mechanism of ICT on EC.

\subsection{Model and Method}

3.2.1. Point Estimation of Direct Impact and Spatial Spillover. The purpose of this study is tantamount to analyze the direct and spillover effects of ICT on EC and their action channels. Considering that spatial econometric modeling technology is a very effective tool to analyze the direct effect and spillover effect $[45,46]$ and the mediation effect model is a very effective tool to analyze the action channels [47-49], this paper introduces these two methods for analysis as follows:

(1) Test Method for Cross-Section Dependence. Before deciding whether it is necessary to introduce a spatial econometric model, it is necessary to judge whether the variables are cross-section dependency. The cross-section dependence (CD) test proposed by Pesaran [50] and the bias-corrected scaled Lagrange multiplier (bias-corrected LM) test proposed by Baltgi et al. [51] are two effective methods to judge whether the cross section is dependent. Among them, the CD test constructs test statistics based on the correlation coefficient of sample regression residual, and the bias-corrected LM method constructs test statistics based 


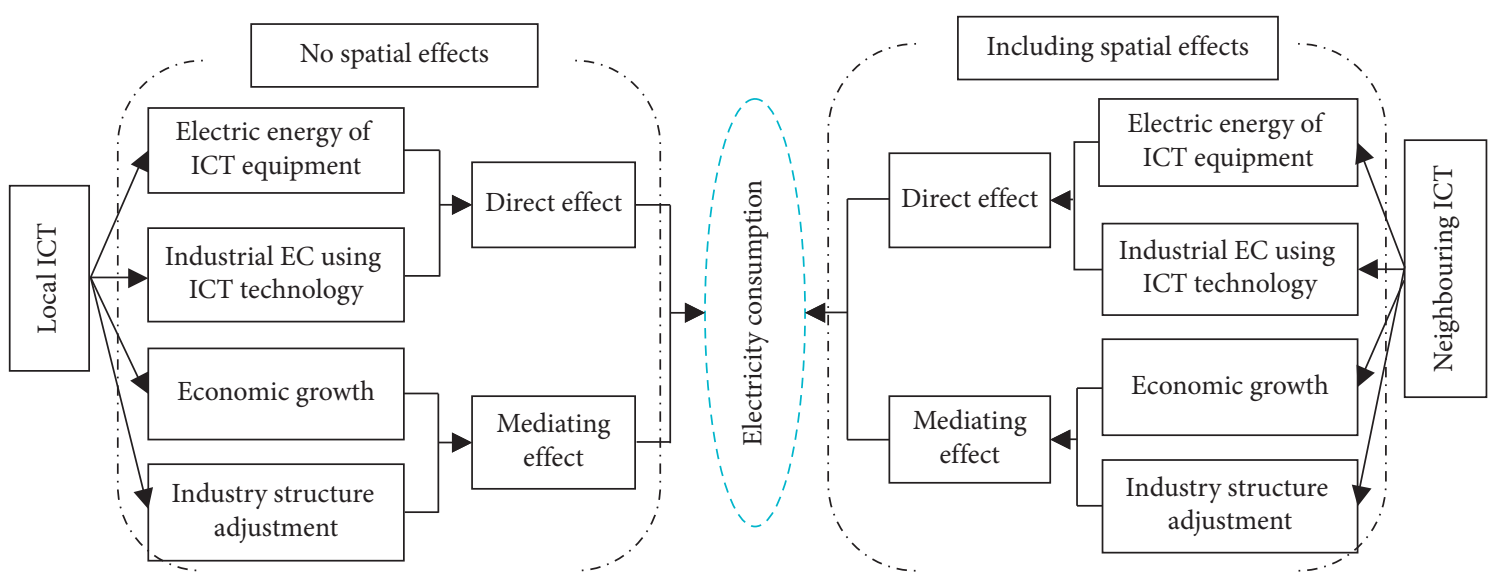

FIgURE 1: Effect mechanism of ICT on EC.

on the square of correlation coefficient of sample regression residual. The formulas are as follows:

$$
\begin{aligned}
\mathrm{CD} & =\sqrt{\frac{2 T}{N(N-1)}\left|\sum_{i=1}^{N-1} \sum_{j=i+1}^{N} \rho_{i j}\right|,} \\
\text { bias - corrected LM } & =\sqrt{\frac{1}{N(N-1)} \sum_{i=1}^{N-1} \sum_{j=i+1}^{N}\left(T \rho_{i j}^{2}-1\right)}-\frac{N}{2(T-1)},
\end{aligned}
$$

where $\rho_{i j}$ is the correlation coefficient of residuals series $i$ and $j$ and its calculation formula is

$$
\rho_{i j}=\frac{\sum_{t=1}^{T} \widehat{\mu}_{i t} \widehat{\mu}_{j t}}{\left|\sum_{t=1}^{T} \widehat{\mu}_{i t}^{2}\right|^{1 / 2}\left|\sum_{t=1}^{T} \widehat{\mu}_{j t}^{2}\right|^{1 / 2}}
$$

where $\widehat{\mu}_{i t}$ is an estimated value of $\mu_{i t}$ based on the least square (LS) regression.

(2) Expression of the Spatial Panel Model. According to the different expression methods of "space" in the setting of spatial panel model, the spatial panel model is mainly divided into two types $[45,46]$ : one is the spatial auto-regression panel model (SAR), which is mainly used to analyze the influence of $\mathrm{EC}$ behavior of neighboring provinces on EC behavior of the local province; the other is spatial error panel model (SEM), in which the relationship between provinces is reflected by error terms. The spatial Durbin model (SDM) contains the endogenous and exogenous variables with spatial lag, which can be regarded as a more general form than SAR and SEM
$[45,46]$. The expressions of SAR, SEM, and SDM are shown in model (4), model (5), and model (6), respectively:

$$
\begin{gathered}
\text { Lnele }_{i t}=\lambda_{0}+\rho W^{*} \text { Lnele }_{i t}+\lambda_{1} \text { Lnict }_{i t} \\
+\zeta_{j} \sum \operatorname{Lnctr}_{j, i t}+\mu_{i t}, \\
\text { Lnele }_{i t}=\lambda_{0}+\lambda_{1} \text { Lnict }_{i t}+\zeta_{j} \sum \operatorname{Lnctr}_{j, i t}+\mu_{i t}, \\
\mu_{i t}=\psi \sum_{j=1}^{N} w_{i j} \mu_{i t}+v_{i t},
\end{gathered}
$$

$$
\begin{array}{r}
\text { Lnele }_{i t}=\lambda_{0}+\rho_{3} W^{*} \text { Lnele }_{i t}+\lambda_{1} \text { Lnict }_{i t}+\zeta_{j} \sum \operatorname{Lnctr}_{j, i t} \\
+\lambda_{1}^{*} W^{*} \text { Lnict }_{i t}+\zeta_{j}^{*} \sum W^{*} \operatorname{Lnctr}_{j, i t}+\mu_{i t},
\end{array}
$$

where ele represents EC, ict represents the development of ICT, ctr represents the control variable, $\mu_{i t}$ is the random disturbance term, $i$ represents the number of the $i$-th unit; $t$ represents the $t$-th period, and $L$ represents logarithmic processing, $W^{*} \operatorname{Ln} X_{i t}=\sum_{j \neq i}^{N} w_{i j} \operatorname{Ln} X_{j t}$. If the weighted spatial interaction items in the model are not significant, then there is no so-called "spillover effect"; otherwise, if one or more spatial weighted interaction items are significant, the "spillover effect" exists.

(3) Selection Method of the Different Spatial Panel Model. In order to judge whether the setting form of the SDM model is appropriate, we applied Wald statistics and likelihood ratio (LR) statistics to judgment $[45,52]$. According to Elhorst $[45,52]$, the Wald statistics and LR statistics are subject to the $\chi^{2}$ distribution of degree of the freedom $k$. If the Wald_spatial_lag statistics and Wald_spatial_error statistics both reject null hypotheses $\left(H_{0}\right)$, it indicates that SDM is 
more reasonable. Likewise, If LR_spatial_lag statistics and LR_spatial_error statistics both reject null hypotheses $\left(H_{0}\right)$, it also indicates that SDM is more reasonable.

(4) Parameter Estimation Strategy of the Spatial Panel Model. The parameters of LS estimation are not only biased but also inconsistent if the model contains the spatial lag explanatory variables. The parameters of LS estimation meet the unbiased and consistent, but no longer meet the validity assumption, if the model contains the spatial error term. Therefore, it is necessary to find an effective alternative method. The maximum likelihood estimation (MLE) method can get unbiased and consistent estimation results $[53,54]$, and Elhorst [54] further proves that this method can effectively solve the endogenous problem.

3.2.2. Partial Differential Method of Direct Impact and Spillover Effect. LeSage and Pace [55] pointed out that the results obtained by the point estimation method may be biased and proposed the partial differential method to calculate the direct effect and spatial spillover effect. If the explained variable is represented by matrix $Y$ and the explaining variable is represented by matrix $X$, the SDM can be rewritten into the following form:

$$
\begin{aligned}
Y= & (I-\delta W)^{-1} \alpha l_{N}+(I-\delta W)^{-1}(X \beta+W X \theta) \\
& +(I-\delta W)^{-1} \varepsilon .
\end{aligned}
$$

Among them, the partial differential of the variable named $Y$ of $N$ regions with respect to the 1 st to $k$-th variables named $X$ is shown as follows:

$\begin{aligned} {\left[\frac{\partial Y}{\partial x_{1 k}} \cdots \frac{\partial Y}{\partial x_{N k}}\right] } & =\left[\begin{array}{ccc}\frac{\partial Y_{1}}{\partial x_{1 k}} & \cdots & \frac{\partial Y_{1}}{\partial x_{N k}} \\ \vdots & \cdots & \vdots \\ \frac{\partial Y_{N}}{\partial x_{1 k}} \cdots & \frac{\partial Y_{N}}{\partial x_{N k}}\end{array}\right] \\ & =(I-\delta W)^{-1}\left[\begin{array}{cccc}\beta_{k} & w_{12} \theta_{k} & \cdots & w_{1 N} \theta_{k} \\ w_{21} \theta_{k} & \beta_{k} & \cdots & w_{2 N} \theta_{k} \\ \vdots & \vdots & \vdots & \vdots \\ w_{N 1} \theta_{k} & w_{N 2} \theta_{k} & \cdots & \beta_{k}\end{array}\right] .\end{aligned}$

Among them, LeSage and Pace [55] defined the mean value of diagonal elements in the rightmost matrix of formula (7) as a direct effect, and the mean value of the sum of nondiagonal elements in each row or column was defined as the spillover effect. In SDM, the direct effect of the $k$-th variable named $X$ on $Y$ is equal to $\beta_{k}$, and the average value of the spillover effect on the adjacent area is $\sum_{\mathrm{i}=1}^{N} \sum_{j=1}^{N} w_{i j} \theta_{k} / N$.

3.2.3. Analysis Method of Action Mechanism. In order to reveal whether ICT has significantly affected China's EC through the channels of economic growth and the adjustment of the industrial structure, according to the practice of Li et al. [48] and Xu et al. [49], the following linear models (9), (10), and (11) are introduced to analyze the mediation role of ICT on EC:

$$
\begin{aligned}
\text { Lnele }_{i t} & =\alpha_{0}+\alpha_{1} \text { Lnict }_{i t}+\alpha_{2} \text { Lnctr }_{i t}+\varepsilon_{1 i t}, \\
\text { Lnmed }_{i t} & =\beta_{0}+\beta_{1} \text { Lnict }_{i t}+\beta_{2} \operatorname{Lnctr}_{i t}+\varepsilon_{2 i t}, \\
\text { Lnele }_{i t} & =\gamma_{0}+\gamma_{1} \text { Lnict }_{i t}+\gamma_{2} \text { Lnmed }_{i t}+\gamma_{3} \operatorname{Lnctr}_{i t}+\varepsilon_{3 i t},
\end{aligned}
$$

where ele represents EC, ict represents the development of ICT, med represents the mediation variables, ctr represents the control variable, and $\varepsilon_{i t}$ is the random disturbance term. Substituting model (10) into model (11), we can get

$$
\begin{array}{r}
\text { Lnele }_{i t}=\left(\gamma_{0}+\gamma_{2} \beta_{0}\right)+\left(\gamma_{1}+\gamma_{2} \beta_{1}\right) \text { Lnict }_{i t} \\
+\left(\gamma_{2} \beta_{2}+\gamma_{3}\right) \\
\operatorname{Lnctr}_{i t}+\varepsilon_{3 i t} .
\end{array}
$$

In model (12), $\gamma_{1}$ is the direct effect of ICT on EC, and $\gamma_{2} \beta_{1}$ is the mediation effect of ICT on EC.

Mediation effect estimation strategy as follows: the first step is to test the significance of the coefficient in the model (9). If the coefficient $\alpha_{1}$ is not significant, it means that ICT is not related to $\mathrm{EC}$, and the mediation effect analysis is stopped; if the coefficient $\alpha_{1}$ is significant, the further test is carried out. The second step is to test the significance of the estimation coefficient $\beta_{1}$ in model (10). If the estimation coefficient $\beta_{1}$ is not significant, the test is stopped; otherwise, the third step is to test. The third step is to test the significance of the estimated coefficients $\gamma_{1}$ and $\gamma_{2}$ in model (11). If the coefficient $\gamma_{2}$ of mediation variables is significant, it indicates that there exists a mediation effect. At this time, consider the significance of the estimated coefficient $\gamma_{1}$. If $\gamma_{1}$ is significant, there exists an incomplete mediation effect; if $\gamma_{1}$ is not significant, there exists a complete mediation effect.

\section{Variables and Data}

4.1. Variables. EC is an explanatory variable. There are two kinds of approaches to measure EC. One way is the aggregate index $[56,57]$; the other way is the average index [58-60]. Per capita EC (avele) is obtained from aggregate EC (toele) divided by the aggregate population. This paper chooses both of them as the explained variable, respectively.

The development of ICT is the main explanatory variable. There are two types of measurement indexes: one is a 
single indicator. For example, some literature used the number of Internet users (net) as an indicator measuring information technology, the number of landline and mobile phone users (tele) as an indicator measuring the use of communication tools $[6,11,14]$, and the industrial added value of telecommunication services (ICTP) measuring the development of ICT industry [13]; the other is to synthesize a comprehensive indicator. Concerning studies combined several indexes such as Internet broadband, Internet users, landline and mobile phone, and computer users into one index to measure the development of ICT based on the principal component analysis (PCA) [12, 21, 35, 61]. Referring to the existing literature and improve its practice, this study chooses Internet users (net), landline, and mobile phones per 100 people (tele) and the industrial added value of telecommunication services (ICTP) to measure the three specific performance of the development of ICT, respectively. Because the first two indicators are highly correlated, and the correlation coefficient is more than 0.83 (see Supplementary Materials (available here)), if adding both of them in the same model may cause multicollinearity, we use the PCA method to reduce the dimensions and extract common factors to measure the development of ICT. The composition index is represented by ICTCI.

The other variables include economic growth, the adjustment of the industrial structure, patent innovation, domestic credit, and import trade. Among them, economic growth is mostly measured by real gross domestic products (RGDP). We use 1999 as the base period, and the real GDP equals the nominal GDP divided by the GDP deflator. The adjustment of the industrial structure is measured by the proportion of the tertiary industry in GDP, which is expressed by str. Patent innovation is measured by the actual number of authorized patents divided by the population at the end of the year, which is represented by pat. Domestic credit is obtained by the year-end credit divided by nominal GDP, which is represented by crd; import trade is calculated by the import amount divided by GDP, which is represented by imp.

It should be pointed out that there are numerous options for the spatial weight matrix $[62,63]$. In this paper, refer to the practice of $\mathrm{Yu}$ et al. [63], economic distance weight $(W)$ is adopted, in which the definition of element $w_{i j}$ in $W$ is as follows: If $i \neq j, w_{i j}=1 /\left|y_{i}-y_{j}\right|$; otherwise, $i=j, w_{i j}=0$, where $y_{i}$ and $y_{j}$ are the average of the real GDP of the $i$-th province and the $j$-th province during the sample period.

4.2. Data. The sample regions include 31 provinces, municipalities, and autonomous regions in the Chinese mainland, with a sample period of 1999-2018 years. The basic data come from China Statistical Yearbook during 2000-2019, China Energy Statistical Yearbook during 2000-2019, China Financial Statistical Yearbook during 2000-2019, China Regional Financial Operation Report during 1999-2018, and National Economic and Social Development Operation Report of each province municipalities, and autonomous regions during 1999-2018. The statistical description of each variable is shown in Table A1 (see Supplementary Materials), and the correlation coefficients are shown in Table A2 (see Supplementary Materials).

\section{Empirical Results and Interpretation}

5.1. Test of Cross-Section Dependence. It is necessary to judge whether the variables are cross-section dependent before we decided to introduce a spatial econometric model. We adopted CD statistics and bias-corrected LM statistics to test whether the variables are cross-section dependent. The results of the cross-section dependence test with CD statistics and bias-corrected LM statistics are shown in Table 1. The CD statistics and bias-corrected LM statistic of Lntoele reject the null hypothesis $\left(H_{0}\right)$ of cross-section independence at the significance level of $1 \%$, which means that the aggregate EC of different provinces is not independent. Likewise, The CD statistics and Bias-corrected LM statistics of Lnavele, Lnictci, Lnnet, Lntele, Lnpat, Lncrd, Lnimp, Lnrgdp, and Lnstr, also reject $H_{0}$ at the level of $1 \%$ significance, which means that the per capita EC, the development of ICT, the number of Internet users, telephone penetration rate, patent innovation, domestic credit, import trade, economic growth, and the adjustment of the industrial structure are also crosssectional dependent, respectively.

\subsection{Direct Effect and Spillover Effect Are Calculated by Point} Estimation Method. Table 2 shows the estimated results of the model (6). $M(1 \mathrm{a}), M(2 \mathrm{a})$, and $M(3 \mathrm{a})$ are the estimation results with Lntoele as the explained variable, and $M(1 \mathrm{~b})$, $M(2 \mathrm{~b})$ and $M(3 \mathrm{~b})$ are the estimation results with Lnavele as the explained variable. According to the Hausman test [64], all of Hausman statistics in $M(1 \mathrm{a}), M(2 \mathrm{a}), M(3 \mathrm{a}), M(1 \mathrm{~b})$, $M(2 \mathrm{~b})$, and $M(3 \mathrm{~b})$ reject the null hypothesis $H_{0}$ at the significance level of $1 \%$, which indicates that the fixed effect form is superior to the random effect form. Wald_spatial_lag statistics, Wald_spatial_error statistics, LR_spatial_lag statistics, and LR_spatial_error statistics in $M(1 \mathrm{a}), M(2 \mathrm{a})$, $M(3 \mathrm{a}), M(1 \mathrm{~b}), M(2 \mathrm{~b})$, and $M(3 \mathrm{~b})$ all reject the null hypothesis $H_{0}$ at the significance level of $1 \%$, which indicates that SDM is suitable, and it is unnecessary to simplify SDM to SAR or SEM. Next, we analyze the meaning of each parameter as follows.

Firstly, the effect of comprehensive development of ICT on EC is analyzed. According to Table 2, the estimated coefficients of the main explanatory variables named Lnictci in $M(1 \mathrm{a})$ and $M(1 \mathrm{~b})$ are 0.2282 and 0.3927 and meets the $t$ test at the significance level of $1 \%$, which means the development of ICT promotes on the aggregate (per capita) EC in China. This further validates the conclusions of Afzal et al. [16], Afzal and Gow [7], Salahuddin and Alam [19], and 
TABLE 1: Cross-section dependence test results of variables.

\begin{tabular}{lcc}
\hline Variable & CD test & Bias-corrected LM \\
\hline Lntoele & $95.14387^{* * *}$ & $279.8158^{* * *}$ \\
Lnavele & $94.74905^{* * *}$ & $277.3882^{* * *}$ \\
Lnictci & $95.83513^{* * *}$ & $284.0940^{* * *}$ \\
Lnnet & $95.74304^{* * *}$ & $283.5191^{* * *}$ \\
Lntele & $94.56901^{* * *}$ & $276.2868^{* * *}$ \\
Lnpat & $92.68280^{* * *}$ & $265.0118^{* * *}$ \\
Lncrd & $61.54365^{* * *}$ & $139.2010^{* * *}$ \\
Lnimp & $67.30324^{* * *}$ & $25.85710^{* * *}$ \\
Lnrgdp & $90.72525^{* * *}$ & $254.5939^{* * *}$ \\
Lnstr & $37.71847^{* * *}$ & $89.00097^{* * *}$ \\
\hline
\end{tabular}

Note: ${ }^{* * *}$ denote significance levels of $1 \%$.

TABLE 2: The effect of ICT on EC.

\begin{tabular}{|c|c|c|c|c|c|c|}
\hline Variable & $\begin{array}{c}\text { Lntoele } \\
\text { Lnictci } \\
M(1 \mathrm{a})\end{array}$ & $\begin{array}{l}\text { Lnavele } \\
\text { Lnictci } \\
M(1 b)\end{array}$ & $\begin{array}{l}\text { Lntoele } \\
\text { Lnnet } \\
M(2 \mathrm{a})\end{array}$ & $\begin{array}{l}\text { Lnavele } \\
\text { Lnnet } \\
M(2 \mathrm{~b})\end{array}$ & $\begin{array}{l}\text { Lntoele } \\
\text { Lntele } \\
M(3 \mathrm{a})\end{array}$ & $\begin{array}{c}\text { Lnavele } \\
\text { Lntele } \\
M(3 \mathrm{~b})\end{array}$ \\
\hline Lnictci & $\begin{array}{c}0.2282^{* * *} \\
{[5.6286]}\end{array}$ & $\begin{array}{c}0.3927^{* * *} \\
{[9.7714]}\end{array}$ & & & & \\
\hline Lnnet & & & $\begin{array}{c}0.1488^{* * *} \\
{[5.8044]}\end{array}$ & $\begin{array}{c}0.2370^{* * *} \\
{[9.6590]}\end{array}$ & & \\
\hline Lntele & & & & & $\begin{array}{c}0.0854^{* * *} \\
{[3.2977]}\end{array}$ & $\begin{array}{c}0.1867^{* * *} \\
{[7.4404]}\end{array}$ \\
\hline Lnpat & $\begin{array}{c}-0.0868^{* * *} \\
{[-4.7190]}\end{array}$ & $\begin{array}{c}-0.0545^{* * * *} \\
{[-2.9899]}\end{array}$ & $\begin{array}{c}-0.0871^{* * *} \\
{[-4.7450]}\end{array}$ & $\begin{array}{c}-0.0531^{* * *} \\
{[-3.0224]}\end{array}$ & $\begin{array}{c}-0.0873^{* * *} \\
{[-4.6512]}\end{array}$ & $\begin{array}{l}-0.0539^{* *} \\
{[-2.9612]}\end{array}$ \\
\hline Lncrd & $\begin{array}{c}0.3219^{* * *} \\
{[8.5908]}\end{array}$ & $\begin{array}{c}0.2500^{* * * *} \\
{[6.7297]}\end{array}$ & $\begin{array}{c}0.3136^{* * *} \\
{[8.3649]}\end{array}$ & $\begin{array}{c}0.2413^{* * *} \\
{[6.7225]}\end{array}$ & $\begin{array}{c}0.3356^{* * *} \\
{[8.7918]}\end{array}$ & $\begin{array}{c}0.2754^{* * *} \\
{[7.4463]}\end{array}$ \\
\hline Lnimp & $\begin{array}{c}-0.0752^{* * *} \\
{[-4.8513]}\end{array}$ & $\begin{array}{l}-0.0439^{* *} \\
{[-2.8566]}\end{array}$ & $\begin{array}{c}-0.0748^{* * *} \\
{[-4.8572]}\end{array}$ & $\begin{array}{l}-0.0424^{* *} \\
{[-2.8744]}\end{array}$ & $\begin{array}{c}-0.0857^{* * *} \\
{[-5.4499]}\end{array}$ & $\begin{array}{c}-0.0592^{* * * *} \\
{[-3.8850]}\end{array}$ \\
\hline Lnrgdp & $\begin{array}{c}0.5132^{* * *} \\
{[5.5988]}\end{array}$ & $\begin{array}{c}0.3930^{* * *} \\
{[4.3242]}\end{array}$ & $\begin{array}{c}0.5146^{* * *} \\
{[5.6485]}\end{array}$ & $\begin{array}{c}0.4127^{* * *} \\
{[4.7308]}\end{array}$ & $\begin{array}{c}0.5401^{* * *} \\
{[5.7920]}\end{array}$ & $\begin{array}{c}0.4209^{* * *} \\
{[4.6581]}\end{array}$ \\
\hline Lnstr & $\begin{array}{c}0.3679^{* * *} \\
{[6.0978]}\end{array}$ & $\begin{array}{c}0.4266^{* * *} \\
{[7.1294]}\end{array}$ & $\begin{array}{c}0.3784^{* * *} \\
{[6.3774]}\end{array}$ & $\begin{array}{c}0.4585^{* * *} \\
{[8.0664]}\end{array}$ & $\begin{array}{c}0.4355^{* * *} \\
{[7.3203]}\end{array}$ & $\begin{array}{c}0.5049^{* * *} \\
{[8.7526]}\end{array}$ \\
\hline$W *$ lnictci & $\begin{array}{l}-0.3499^{* *} \\
{[-2.3465]}\end{array}$ & $\begin{array}{l}-0.2657^{*} \\
{[-1.7711]}\end{array}$ & & & & \\
\hline$W *$ Lnnet & & & $\begin{array}{l}-0.1880^{*} \\
{[-1.9484]}\end{array}$ & $\begin{array}{c}-0.1434 \\
{[-1.5282]}\end{array}$ & & \\
\hline$W *$ Lntele & & & & & $\begin{array}{l}-0.1325^{*} \\
{[-1.7172]}\end{array}$ & $\begin{array}{c}-0.0718 \\
{[-0.9447]}\end{array}$ \\
\hline$W *$ Lnpat & $\begin{array}{c}-0.1434^{* *} \\
{[-2.3939]}\end{array}$ & $\begin{array}{l}-0.1471^{* *} \\
{[-2.4807]}\end{array}$ & $\begin{array}{c}-0.1288^{* * *} \\
{[-2.1521]}\end{array}$ & $\begin{array}{c}-0.1283^{* *} \\
{[-2.2418]}\end{array}$ & $\begin{array}{l}-0.1597^{* *} \\
{[-2.5996]}\end{array}$ & $\begin{array}{c}-0.1718^{* * *} \\
{[-2.8882]}\end{array}$ \\
\hline$W *$ Lncrd & $\begin{array}{c}0.2062 \\
{[1.1986]}\end{array}$ & $\begin{array}{l}0.3609^{* *} \\
{[2.1264]}\end{array}$ & $\begin{array}{c}0.1773 \\
{[1.0406]}\end{array}$ & $\begin{array}{l}0.3765^{* *} \\
{[2.3152]}\end{array}$ & $\begin{array}{c}0.1379 \\
{[0.8167]}\end{array}$ & $\begin{array}{l}0.3298^{* *} \\
{[2.0224]}\end{array}$ \\
\hline$W *$ Lnimp & $\begin{array}{l}-0.0678^{*} \\
{[-1.7167]}\end{array}$ & $\begin{array}{c}-0.0122 \\
{[-0.3128]}\end{array}$ & $\begin{array}{l}-0.0722^{*} \\
{[-1.8548]}\end{array}$ & $\begin{array}{c}-0.0146 \\
{[-0.3932]}\end{array}$ & $\begin{array}{l}-0.0762^{* *} \\
{[-1.8697]}\end{array}$ & $\begin{array}{c}-0.0312 \\
{[-0.7914]}\end{array}$ \\
\hline$W *$ Lnrgdp & $\begin{array}{c}2.2355^{* * *} \\
{[5.7515]}\end{array}$ & $\begin{array}{c}2.5934^{* * *} \\
{[6.7389]}\end{array}$ & $\begin{array}{c}2.0418^{* * * *} \\
{[5.5031]}\end{array}$ & $\begin{array}{c}2.5087^{* * *} \\
{[7.0674]}\end{array}$ & $\begin{array}{c}2.3397^{* * *} \\
{[5.8332]}\end{array}$ & $\begin{array}{c}2.7896^{* * * *} \\
{[7.1864]}\end{array}$ \\
\hline$W *$ Lnstr & $\begin{array}{c}-0.9695^{* * *} \\
{[-5.2921]}\end{array}$ & $\begin{array}{c}-0.7151^{* * *} \\
{[-3.8962]}\end{array}$ & $\begin{array}{c}-0.9306^{* * *} \\
{[-5.0907]}\end{array}$ & $\begin{array}{c}-0.5646^{* * *} \\
{[-3.1624]}\end{array}$ & $\begin{array}{c}-1.0367^{* * *} \\
{[-5.4160]}\end{array}$ & $\begin{array}{c}-0.7083^{* * *} \\
{[-3.7419]}\end{array}$ \\
\hline$W *$ Dep.var. & $\begin{array}{c}0.1196 \\
{[1.6171]}\end{array}$ & $\begin{array}{c}-0.0594 \\
{[-0.7907]}\end{array}$ & $\begin{array}{l}0.1568^{* *} \\
{[2.1600]}\end{array}$ & $\begin{array}{l}-0.1510^{* *} \\
{[-1.9299]}\end{array}$ & $\begin{array}{l}0.1841^{* *} \\
{[2.5446]}\end{array}$ & $\begin{array}{l}-0.0970 \\
{[-1.2541]}\end{array}$ \\
\hline$R$-squared & 0.9898 & 0.9775 & 0.9899 & 0.9773 & 0.9893 & 0.9756 \\
\hline Corr-squared & 0.5038 & 0.5545 & 0.5057 & 0.5507 & 0.4788 & 0.5175 \\
\hline Log likelihood & 473.8777 & 478.85102 & 475.2999 & 476.0878 & 459.61325 & -2178.122 \\
\hline Wald_spatial_lag & $73.1734^{* * *}$ & $63.7459^{* * *}$ & $67.975^{* * *}$ & $63.0889^{* * *}$ & $74.0587^{* * *}$ & $75.855^{* * *}$ \\
\hline LR_spatial_lag & $73.3308^{* * *}$ & $64.6918^{* * *}$ & $67.7502^{* * *}$ & $59.4992^{* * *}$ & $74.424^{* * *}$ & $71.0421^{* * *}$ \\
\hline Wald_spatial_error & $73.3840^{* * *}$ & $62.5727^{* * *}$ & $68.3616^{* * *}$ & $60.6834^{* * *}$ & $75.5035^{* * *}$ & $72.5566^{* * *}$ \\
\hline LR_spatial_error & $72.6930^{* * *}$ & $62.3797^{* * *}$ & $67.2241^{* * *}$ & $57.7388^{* * *}$ & $73.9207^{* * *}$ & $68.6425^{* * *}$ \\
\hline Hausman test & $754.3281^{* * *}$ & $90.6921^{* * *}$ & $103.2146^{* * *}$ & $51.6559^{* * *}$ & $60.0381^{* * *}$ & $138.9592^{* * *}$ \\
\hline Method & MLE & MLE & MLE & MLE & MLE & MLE \\
\hline Obs. & 620 & 620 & 620 & 620 & 620 & 620 \\
\hline
\end{tabular}

Note: ${ }^{*},{ }^{* *}$, and ${ }^{* * *}$ denote significance levels of $10 \%, 5 \%$, and $1 \%$; the values in square brackets are $t$ statistics. 
Solarin et al. [61] and reconfirm that the use of ICT promotes electricity demand. The estimated parameter of $W *$ Lnictci in $M(1 \mathrm{a})$ and $M(1 \mathrm{~b})$ are -0.1434 and -0.2657 and meets the $t$-test at the significance level of $5 \%$ and $10 \%$, respectively, which indicates the spillover effect of ICT is negatively correlated with the aggregate (per capita) EC. This means that the development of ICT in neighboring provinces is not conducive to aggregate (per capita) EC in local regions. This may be related to the existence of competitive relationship between neighboring regions.

Secondly, the differential effect of ICT on EC is compared. According to Table 2, the estimated coefficients of Lnnet in $M(2 \mathrm{a})$ and $M(2 \mathrm{~b})$ are 0.1488 and 0.2370 , the estimated coefficients of Lntele in $M(3 \mathrm{a})$ and $M(3 \mathrm{~b})$ are 0.0854 and 0.1867 , and all of them meet the $t$-test at the significance of $1 \%$, which confirms that the use of the Internet and communication tools both directly contribute to aggregate (per capita) EC, and the direct role of Internet use is slightly greater than that of information and communication tools. It is consistent with the results of Afzal et al. [16] and Saidi et al. [14], and those studies also prove that the use of the Internet and communication tools stimulate EC. The estimated coefficients of $W *$ Lnnet in $M(2 \mathrm{a})$ and $M(2 \mathrm{~b})$ are -0.1880 and 0.1434 , and only the former meets the $t$-test at $10 \%$ significance level, which only confirms that the use of the Internet has a significant negative spillover effect on aggregate EC; the estimated coefficients of $W *$ Lntele in $M(3 a)$ and $M(3 b)$ are -0.1325 and -0.0718 , and the first estimated coefficient meets the $t$-test at a significance level of $10 \%$, which only confirms that the popularization of communication tools has a significant negative spillover effect on aggregate EC.

Finally, we further analyze the parameter estimation results of different control variable. According to Table 2, the estimated coefficients of Lnpat in $M(1 \mathrm{a}), M(2 \mathrm{a}), M(3 \mathrm{a})$, $M(1 \mathrm{~b}), M(2 \mathrm{~b})$, and $M(3 \mathrm{~b})$ are significantly negative, which indicates that patent innovation is conducive to aggregate (per capita) electricity-saving. This supports the conclusion of An et al. [44].The estimated coefficients of $W *$ Lnpat in $M(1 \mathrm{a}), M(2 \mathrm{a}), M(3 \mathrm{a}) M(1 \mathrm{~b}), M(2 \mathrm{~b})$, and $M(3 \mathrm{~b})$ are significantly negative, which indicate that the spillover effect of patent innovation is not conducive to aggregate (per capita) EC.

The estimated coefficients of Lncrd in $M(1 \mathrm{a}), M(2 \mathrm{a})$, $M(3 \mathrm{a}) M(1 \mathrm{~b}), M(2 \mathrm{~b})$, and $M(3 \mathrm{~b})$ are significantly positive, which indicates that the direct effect of domestic credit promotes aggregate (per capita) EC, and this supports the conclusion of Lin and Zhao [41] and Rafindadi and Ozturk [65], who deemed there existed a significant promotion effect of financial development on renewable EC. The estimated coefficients of $W *$ Lncrd in $M(1 \mathrm{a}), M(2 \mathrm{a})$, and $M(3 \mathrm{a})$ are insignificantly positive, and the estimated coefficients of $W *$ Lncrd in $M(1 \mathrm{~b}), M(2 \mathrm{~b})$, and $M(3 \mathrm{~b})$ are significantly positive, which indicate that the spillover effect of domestic credit promotes per capita EC.

The estimated coefficients of Lnimp in $M(1 \mathrm{a}), M(2 \mathrm{a})$, $M(3 \mathrm{a}), M(1 \mathrm{~b}), M(2 \mathrm{~b})$, and $M(3 \mathrm{~b})$ are significantly negative, which indicates that the direct effect of import trade is not conducive to aggregate (per capita) EC and it only partially supports the conclusion of Lin and Zhao [41]; they deemed that trade open had a significant negative effect on renewable EC in the long-run. The estimated coefficient of $W *$ Lnimp in $M(1 \mathrm{a}), M(2 \mathrm{a})$, and $M(3 \mathrm{a})$ is significantly negative, and the estimated coefficient of $W *$ Lnimp in $M(1 \mathrm{~b}), M(2 \mathrm{~b})$, and $M(3 b)$ is insignificantly negative, which only confirms that the direct effect of import trade is not conducive to aggregate EC.

The estimated coefficients of Lnrgdp in $M(1 \mathrm{a}), M(2 \mathrm{a})$, $M(3 \mathrm{a}) M(1 \mathrm{~b}), M(2 \mathrm{~b})$, and $M(3 \mathrm{~b})$ are significantly positive, which means economic growth promotes to aggregate (per capita) EC. This is consistent with the conclusion of Hamdi et al. [28], Osman et al. [36], and Saidi et al. [14]. All these studies confirmed that there existed a positive and statistically significant effect of economic growth on EC. The estimated coefficients of $W *$ Lnrgdp in $M(1 \mathrm{a}), M(2 \mathrm{a})$, $M(3 \mathrm{a}) M(1 \mathrm{~b}), M(2 \mathrm{~b})$, and $M(3 \mathrm{~b})$ are significantly positive, and it means that the spillover effect of economic growth similarly promotes to aggregate (per capita) EC.

The estimated coefficients of Lnstr in $M(1 \mathrm{a}), M(2 \mathrm{a})$, $M(3 \mathrm{a}) M(1 \mathrm{~b}), M(2 \mathrm{~b})$, and $M(3 \mathrm{~b})$ are significantly positive, which indicates the direct effect of the adjustment of the industry structure promotes to aggregate (per capita) EC. It is consistent with the conclusion of Liu et al. [66]. The estimated coefficients of $W *$ Lnstr in $M(1 \mathrm{a}), M(2 \mathrm{a}), M(3 \mathrm{a})$, $M(1 \mathrm{~b}), M(2 \mathrm{~b})$, and $M(3 \mathrm{~b})$ are significantly negative, which indicates that the spillover effect of the adjustment of the industry structure does not contribute to aggregate (per capita) EC.

5.3. Direct Effect and Spillover Effect Are Calculated by the Partial Differential Method. In order to get the robustness results, we applied the partial differential method to calculate the direct effect and spillover effect. Table 3 is the decomposition results of the effect of on EC.

According to Table 3, the direct effect of Lnictci on Lntoele (Lnavele) is $0.2273(0.3945)$, and it meets the $t$-test at $1 \%$ significance level; the spillover effect of Lnictci on Lntoele (Lnavele) is $-0.3559(-0.2764)$, and it meets the significant $t$-test, which indicates that the development of ICT has a positive direct effect and a negative spillover effect on aggregate (per capita) EC. Comparison of the direct and spillover effect of the usage of Internet and communication tools on aggregate (per capita) EC, the direct effect of Lnnet and Lntele on Lntoele (Lnavele) are 0.1491 (0.2370) and $0.0833(0.1870)$, respectively, and all of them are significant, which confirms the direct promotion role of the information technology and communication technology on aggregate (per capita) EC. This is consistent with the corresponding results based on point estimation in Table 2. The spillover effect of $W *$ Lnnet on Lntoele (Lnavele) is $-0.1704(-0.1750)$, and it meets the $t$-test at $10 \%$ significance level, which confirms the spillover effect of the usage of Internet is not conducive to aggregate (per capita) EC. The 
TABle 3: Decomposition results of the effect of on EC.

\begin{tabular}{|c|c|c|c|c|c|c|}
\hline & Lntoele & Lnavele & Lntoele & Lnavele & Lntoele & Lnavele \\
\hline \multicolumn{7}{|c|}{ Direct effect } \\
\hline Lnictci & $\begin{array}{c}0.2273^{* * *} \\
{[5.7050]}\end{array}$ & $\begin{array}{c}0.3945^{* * *} \\
{[9.7906]}\end{array}$ & & & & \\
\hline Lnnet & & & $\begin{array}{c}0.1491^{* * *} \\
{[5.7698]}\end{array}$ & $\begin{array}{c}0.2370^{* * *} \\
{[9.1461]}\end{array}$ & & \\
\hline Lntele & & & & & $\begin{array}{c}0.0833^{* * *} \\
{[3.2080]}\end{array}$ & $\begin{array}{c}0.1870^{* * *} \\
{[7.3116]}\end{array}$ \\
\hline Lnpat & $\begin{array}{c}-0.0875^{* * *} \\
{[-4.7275]}\end{array}$ & $\begin{array}{c}-0.0547^{* *} \\
{[-2.9275]}\end{array}$ & $\begin{array}{c}-0.0862^{* * *} \\
{[-4.7214]}\end{array}$ & $\begin{array}{c}-0.0539^{* *} \\
{[-2.9948]}\end{array}$ & $\begin{array}{c}-0.0884^{* * *} \\
{[-4.7087]}\end{array}$ & $\begin{array}{c}-0.0548^{* *} \\
{[-8354]}\end{array}$ \\
\hline Lncrd & $\begin{array}{c}0.3229^{* * * *} \\
{[8.6783]}\end{array}$ & $\begin{array}{c}0.2476^{* * *} \\
{[6.4833]}\end{array}$ & $\begin{array}{c}0.3134^{* * *} \\
{[8.5880]}\end{array}$ & $\begin{array}{c}0.2394^{* * *} \\
{[6.2488]}\end{array}$ & $\begin{array}{c}0.3370^{* * * *} \\
{[8.8832]}\end{array}$ & $\begin{array}{c}0.2754^{* * *} \\
{[6.9751]}\end{array}$ \\
\hline Lnimp & $\begin{array}{c}-0.0752^{* * *} \\
{[-4.8878]}\end{array}$ & $\begin{array}{c}-0.0435^{* *} \\
{[-2.8359]}\end{array}$ & $\begin{array}{c}-0.0748^{* * *} \\
{[-4.9918]}\end{array}$ & $\begin{array}{c}-0.0423^{* *} \\
{[-2.8015]}\end{array}$ & $\begin{array}{c}-0.0864^{* * *} \\
{[-5.5962]}\end{array}$ & $\begin{array}{r}-0.0590^{* *} \\
{[-3.6103]}\end{array}$ \\
\hline Lnregdp & $\begin{array}{c}0.5205^{* * *} \\
{[5.5756]}\end{array}$ & $\begin{array}{c}0.3929^{* * *} \\
{[4.3803]}\end{array}$ & $\begin{array}{c}0.5124^{* * *} \\
{[5.6917]}\end{array}$ & $\begin{array}{c}0.4166^{* * *} \\
{[4.5843]}\end{array}$ & $\begin{array}{c}0.5590^{* * *} \\
{[6.0933]}\end{array}$ & $\begin{array}{c}0.4299^{* * *} \\
{[4.5505]}\end{array}$ \\
\hline Lnstr & $\begin{array}{c}0.3614^{* * *} \\
{[5.8933]}\end{array}$ & $\begin{array}{c}0.4254^{* * *} \\
{[7.0928]}\end{array}$ & $\begin{array}{c}0.3727^{* * *} \\
{[6.7117]}\end{array}$ & $\begin{array}{c}0.4629^{* * *} \\
{[7.9998]}\end{array}$ & $\begin{array}{c}0.4272^{* * *} \\
{[7.1016]}\end{array}$ & $\begin{array}{c}0.5092^{* * *} \\
{[8.2144]}\end{array}$ \\
\hline \multicolumn{7}{|c|}{ Spillover effect } \\
\hline Lnictci & $\begin{array}{c}-0.3559^{* *} \\
{[-2.0978]}\end{array}$ & $\begin{array}{l}-0.2764^{*} \\
{[-1.9075]}\end{array}$ & & & & \\
\hline Lnnet & & & $\begin{array}{l}-0.1704^{*} \\
{[-1.8278]}\end{array}$ & $\begin{array}{c}-0.1750^{*} \\
{[-1.8133]}\end{array}$ & & \\
\hline Lntele & & & & & $\begin{array}{c}-0.1423 \\
{[-1.4288]}\end{array}$ & $\begin{array}{l}-0.0934^{*} \\
{[-1.1479]}\end{array}$ \\
\hline Lnpat & $\begin{array}{c}-0.1758^{* *} \\
{[-2.5027]}\end{array}$ & $\begin{array}{c}-0.1380^{* * *} \\
{[-2.3421]}\end{array}$ & $\begin{array}{c}-0.1457^{* *} \\
{[-2.2855]}\end{array}$ & $\begin{array}{c}-0.1193^{* * *} \\
{[-2.0264]}\end{array}$ & $\begin{array}{l}-0.2162^{* *} \\
{[-2.6449]}\end{array}$ & $\begin{array}{c}-0.1769^{* * *} \\
{[-2.6518]}\end{array}$ \\
\hline Lncrd & $\begin{array}{c}0.2717 \\
{[1.3830]}\end{array}$ & $\begin{array}{c}0.3243^{* *} \\
{[1.9747]}\end{array}$ & $\begin{array}{l}0.2395 \\
{[1.4360]}\end{array}$ & $\begin{array}{l}0.3311^{* *} \\
{[1.9996]}\end{array}$ & $\begin{array}{c}0.2462 \\
{[1.1580]}\end{array}$ & $\begin{array}{c}0.3044^{* *} \\
{[1.7445]}\end{array}$ \\
\hline Lnimp & $\begin{array}{l}-0.0905^{*} \\
{[-1.9240]}\end{array}$ & $\begin{array}{c}-0.0114 \\
{[-0.3147]}\end{array}$ & $\begin{array}{c}-0.0820^{* *} \\
{[-2.0128]}\end{array}$ & $\begin{array}{l}-0.0095 \\
{[-.2561]}\end{array}$ & $\begin{array}{l}-0.1129^{* *} \\
{[-2.1466]}\end{array}$ & $\begin{array}{c}-0.0292 \\
{[-0.6985]}\end{array}$ \\
\hline Lnregdp & $\begin{array}{c}2.5965^{* * *} \\
{[5.0634]}\end{array}$ & $\begin{array}{c}2.4499^{* * *} \\
{[5.6061]}\end{array}$ & $\begin{array}{c}2.1843^{* * *} \\
{[5.2138]}\end{array}$ & $\begin{array}{c}2.3812^{* * *} \\
{[5.8863]}\end{array}$ & $\begin{array}{c}3.0187^{* * *} \\
{[5.4203]}\end{array}$ & $\begin{array}{c}2.8077^{* * * *} \\
{[5.9825]}\end{array}$ \\
\hline Lnstr & $\begin{array}{c}-1.0508^{* * *} \\
{[-4.5564]}\end{array}$ & $\begin{array}{c}-0.7016^{* * *} \\
{[-3.9559]}\end{array}$ & $\begin{array}{c}-0.8890^{* * *} \\
{[-4.4858]}\end{array}$ & $\begin{array}{c}-0.6459^{* * *} \\
{[-3.7180]}\end{array}$ & $\begin{array}{c}-1.1980^{* * *} \\
{[-4.5885]}\end{array}$ & $\begin{array}{c}-0.8088^{* * *} \\
{[-3.8529]}\end{array}$ \\
\hline
\end{tabular}

Notes: ${ }^{*},{ }^{* *}$, and ${ }^{* * *}$ denote significance levels of $10 \%, 5 \%$, and $1 \%$; the values in square brackets are $t$ statistics.

spillover effect of $W *$ Lntele on Lntoele (Lnavele) is $-0.1423(-0.0934)$. However, neither of them passed the significance $t$-test

In addition to that, according to Table 3, the direct effects of Lnpat and Lnimp on aggregate (per capita) EC are significantly negative; the direct effects of Lncrd, Lnrgdp, and Lnstr on aggregate (per capita) EC are significantly positive. They are consistent with the results of the point estimation method.

The spillover effects of Lnpat, Lnimp, and Lnstr on aggregate (per capita) EC are significantly negative; the spillover effects of Lncrd and Lnrgdp on aggregate (per capita) EC are significantly positive. They are consistent with the corresponding results of the point estimation method.

5.4. Empirical Test of Action Channels. We introduce the mediation effect model to analyze the action channels of ICT affecting EC. According to the test steps of the mediation effect model, the first step is to fit model (9). We take Lntoele and Lnavele as the explained variables, respectively, and take Lnictci as the explanatory variables to obtain the estimated coefficients $\alpha 1$ in $M(4 \mathrm{a})$ and $M(4 \mathrm{~b})$, which are 0.4710 and 0.6499 at the significance level of $1 \%$, respectively (see Table 4) and confirm the direct effect of ICT on aggregate EC and per capita EC; the second step is to estimate model (10), in which the mediation variables named Lnrgdp and Lnstr are taken as the explanatory variables, and the estimated coefficients $\beta 1$ of Lnictic in $M(5 a)$ and $M(5 b)$ are 0.1287 and 0.3581 , respectively, and both meet the significant $t$-test, indicating that the development of ICT is conducive to economic growth and adjustment of the industry structure; the third step to estimate model (11), the estimated coefficients $\gamma 1$ of Lnictci in $M(6 a)$ and $M(6 b)$ are 0.2461 and 0.4174 , which meet the requirement of $1 \%$ significant $t$-test. In addition, the estimated coefficients of Lnrgdp and Lnstr in $M(6 a)$ are 0.5329 and 0.4366 , respectively, and both of them meet the significant $t$-test. The results show that the 
TABLE 4: Estimation results of mediation effect model with the full sample.

\begin{tabular}{|c|c|c|c|c|c|c|}
\hline \multirow[b]{2}{*}{ Variable } & \multicolumn{2}{|c|}{ Step 1: estimation model (9) } & \multicolumn{2}{|c|}{ Step 2: estimation model (10) } & \multicolumn{2}{|c|}{ Step 3: estimation model (11) } \\
\hline & $\begin{array}{l}\text { Lntoele } \\
M(4 a)\end{array}$ & $\begin{array}{c}\text { Lnavele } \\
M(4 \mathrm{~b})\end{array}$ & $\begin{array}{l}\text { Lnrgdp } \\
M(5 \mathrm{a})\end{array}$ & $\begin{array}{l}\text { Lnstr } \\
M(5 b)\end{array}$ & $\begin{array}{c}\text { Lntoele } \\
M(6 a)\end{array}$ & $\begin{array}{c}\text { Lnavele } \\
M(6 \mathrm{~b})\end{array}$ \\
\hline Lnictci & $\begin{array}{l}0.4710^{* * *} \\
{[12.7310]}\end{array}$ & $\begin{array}{l}0.6499^{* * *} \\
{[17.7647]}\end{array}$ & $\begin{array}{c}0.1287^{* * *} \\
{[8.3708]}\end{array}$ & $\begin{array}{l}0.3581^{* * *} \\
{[14.7677]}\end{array}$ & $\begin{array}{c}0.2461^{* * *} \\
{[6.1439]}\end{array}$ & $\begin{array}{l}0.4174^{* * *} \\
{[10.5767]}\end{array}$ \\
\hline Lnpat & $\begin{array}{c}-0.0272 \\
{[-1.4474]}\end{array}$ & $\begin{array}{c}0.0000 \\
{[0.0003]}\end{array}$ & $\begin{array}{c}0.0296^{* * *} \\
{[3.7804]}\end{array}$ & $\begin{array}{l}0.0229^{*} \\
{[1.8566]}\end{array}$ & $\begin{array}{c}-0.0530^{* * *} \\
{[-3.0331]}\end{array}$ & $\begin{array}{c}-0.0233 \\
{[-1.3534]}\end{array}$ \\
\hline Lncrd & $\begin{array}{c}0.3522^{* * *} \\
{[9.0351]}\end{array}$ & $\begin{array}{c}0.2723^{* * *} \\
{[7.0657]}\end{array}$ & $\begin{array}{c}-0.0716^{* * *} \\
{[-4.4222]}\end{array}$ & $\begin{array}{c}0.0340 \\
{[1.3311]}\end{array}$ & $\begin{array}{l}0.3755^{* * *} \\
{[10.2921]}\end{array}$ & $\begin{array}{c}0.2834^{* * * *} \\
{[7.8840]}\end{array}$ \\
\hline Lnimp & $\begin{array}{c}-0.0848^{* * *} \\
{[-5.1961]}\end{array}$ & $\begin{array}{c}-0.0428^{* * *} \\
{[-2.6546]}\end{array}$ & $\begin{array}{c}-0.0190^{* * *} \\
{[-2.7973]}\end{array}$ & $\begin{array}{c}0.0140 \\
{[1.3099]}\end{array}$ & $\begin{array}{c}-0.0808^{* * *} \\
{[-5.3469]}\end{array}$ & $\begin{array}{c}-0.0424^{* * *} \\
{[-2.8507]}\end{array}$ \\
\hline Lnrgdp & & & & & $\begin{array}{c}0.5329^{* * *} \\
{[5.8152]}\end{array}$ & $\begin{array}{c}0.3953^{* * * *} \\
{[4.3783]}\end{array}$ \\
\hline Lnstr & & & & & $\begin{array}{c}0.4366^{* * *} \\
{[7.5119]}\end{array}$ & $\begin{array}{c}0.5072^{* * *} \\
{[8.8581]}\end{array}$ \\
\hline$R^{2}$ & 0.3350 & 0.4068 & 0.1545 & 0.2831 & 0.4425 & 0.5063 \\
\hline Log likelihood & 382.4923 & 389.4710 & 926.8840 & 644.4934 & 437.1531 & 446.3790 \\
\hline Method & LS & LS & LS & LS & LS & LS \\
\hline Obs. & 620 & 620 & 620 & 620 & 620 & 620 \\
\hline
\end{tabular}

Notes: ${ }^{*}, *$, and ${ }^{* * *}$ denote significance levels of $10 \%, 5 \%$, and $1 \%$; the values in square brackets are $t$ statistics.

incomplete mediation effect exists. Among them, the mediation effect of ICT on aggregate EC through the channel of economic growth and the adjustment of the industrial structure is 0.2249 . The estimated coefficients of Lnrgdp and Lnstr in $M(6 \mathrm{~b})$ are 0.3953 and 0.5072 , respectively, and both of them meet the $t$-test at the significance of $1 \%$. The results show that the incomplete mediation effect exists. Among them, the mediation effect of ICT on per capita EC through the channels of economic growth, and the adjustment of the industrial structure is 0.2325 .

\section{Conclusions and Discussion}

The widespread use of ICT has a significant effect on EC. Theoretical analysis shows that local and neighboring ICT can lead to the growth of local EC because of the EC of ICT equipment and the development of related industries. At the same time, it can also reduce the EC because of the application of local and adjacent ICT. In order to better understand the complex relationship between ICT and EC, based on the panel data of 31 provinces in China, this paper introduces spatial modeling techniques and the mediation effect model to investigate the effects of ICT on China's EC and their action channels. The conclusions are as follows.

Firstly, the point estimation results of SDM are basically consistent with those of partial differential method, which show that the direct effect of ICT significantly promotes EC, while the spillover effect is opposite. This means that ignoring the spatial spillover effect will overestimate the total impact of ICT on EC. This provides new empirical evidence for us to fully understand the impact of ICT on EC. The conclusion also has some enlightenment for the prediction of EC. In the process of electricity demand forecasting, it is necessary to integrate ICT factors into prediction model. If the ICT factor is not included as an explanatory variable, it may miscalculate the actual electricity demand, which in turn will cause a shortage or surplus of electricity demand.
Secondly, there exists an incomplete mediating effect when the ICT influences EC through the action channels of economic growth and the adjustment of the industrial structure. This means that ignoring the indirect effect of incomplete mediating effect may overestimate the direct effect of ICT on EC. The policy implication of this conclusion is that controlling the speed of economic growth and optimizing the industrial structure may serve to bring down the pressure of the gap between electricity supply and electricity demand. Specifically speaking, related means such as eliminating the high electricity consuming industries or transforming the high electricity consuming industries into low electricity consuming industries through technological transformation, or promoting the development of emerging low electricity consuming industries are all effective ways to reduce electricity consuming.

Thirdly, the direct and spillover effects of domestic credit on EC are significantly positive, while innovation and import are just the opposite. The result means that it is difficult to effectively control the excessive growth of electricity consumption by controlling the domestic credit scale, while innovation and import may be an effective means for electricity-saving in China. Therefore, related policy should support the development of clean power generation technology, encourage enterprises to adopt clean production technology, and encourage development and application of electricity-saving technologies and products; in terms of import, the government should actively cultivate all kinds of importers and give priority to the introduction of electricitysaving technologies and products.

Admittedly, there are still some limitations and inadequacies in this study. First of all, the stability of the results of spatial panel regression is affected by the selection of spatial weight. In addition to the economic distance already adopted in this study, there are many alternatives such as the spatial weight matrix, such as binary contiguity matrix, geographic distance matrix, and institutional distance 
matrix. How to select appropriate spatial weights is also an unsolved problem. Secondly, when we analyze the role of mediation variables, this paper only considers the role of economic growth and the adjustment of the industrial structure. Perhaps ICT can also affect EC by the channel of improving productivity, promoting population migration, and so on. These channels are not taken into account in this paper. Thirdly, the influence of ICT on EC in each industry perhaps is also heterogeneous, which should be paid more attention in the future.

\section{Data Availability}

The data used to support the findings of this study are included in Section 3.2. All data can also be obtained from the EPS website: http://olap.epsnet.com.cn/.

\section{Conflicts of Interest}

The authors declare no conflicts of interest.

\section{Acknowledgments}

This work was sponsored by the National Natural Science Foundation of China (no. 71773057); Humanities and Social Sciences Research Youth Foundation Project of Ministry of Education in China (no. 16YJCZH124; 17YJCZH218); and Key Funding Projects of Humanities and Social Sciences of Universities in Zhejiang Province (no. 2016QN005).

\section{Supplementary Materials}

Table A1: description statistics of variables. Table A2: correlation matrix. (Supplementary Materials)

\section{References}

[1] J. D. Moyer and B. B. Hughes, "ICTs: do they contribute to increased carbon emissions?" Technological Forecasting and Social Change, vol. 79, no. 5, pp. 919-931, 2012.

[2] M. Shahiduzzaman and K. Alam, "Information technology and its changing roles to economic growth and productivity in Australia," Telecommunications Policy, vol. 38, no. 2, pp. 125-135, 2014.

[3] W. Walker, "Information technology and the use of energy," Energy Policy, vol. 13, no. 5, pp. 458-476, 1985.

[4] R. Bernstein and R. Madlener, "Impact of disaggregated ICT capital on electricity intensity in European manufacturing," Applied Economics Letters, vol. 17, no. 17, pp. 1691-1695, 2010.

[5] Greenpeace International, Clicking Clean: How Companies Are Creating the Green Internet April 2014, SB Business Weekly, Greenpeace International, Amsterdam, Netherlands, 2014.

[6] P. Sadorsky, "Information communication technology and electricity consumption in emerging economies," Energy Policy, vol. 48, pp. 130-136, 2012.

[7] M. Afzal and J. Gow, "Electricity consumption and information and communication technology in the next eleven emerging economies," International Journal of Energy Economics and Policy, vol. 6, no. 3, pp. 381-388, 2016.
[8] S. Faucheux and I. Nicolaï, "IT for green and green IT: a proposed typology of eco-innovation," Ecological Economics, vol. 70, no. 11, pp. 2020-2027, 2011.

[9] International Energy Agency (IEA), Gadgets and Gigawatts: Policies for Energy Efficient Electronics, OECD Publishing, Paris, France, 2009.

[10] B. Schlomann, W. Eichhammer, and L. Stobbe, "Energy saving potential of information and communication technology," International Journal of Decision Support Systems, vol. 1, no. 2, pp. 152-163, 2015.

[11] M. Salahuddin and K. Alam, "Internet usage, electricity consumption and economic growth in Australia: a time series evidence," Telematics and Informatics, vol. 32, no. 4, pp. 862-878, 2015.

[12] M. Shahbaz, I. U. Rehman, R. Sbia, and H. Hamdi, "The role of information communication technology and economic growth in recent electricity demand: fresh evidence from combine cointegration approach in UAE," Journal of the Knowledge Economy, vol. 7, no. 3, pp. 797-818, 2016.

[13] B. Han, D. Wang, W. Ding, and L. Han, "Effect of information and communication technology on energy consumption in China," Natural Hazards, vol. 84, no. 1, pp. 297-315, 2016.

[14] K. Saidi, H. Toumi, and S. Zaidi, "Impact of information communication technology and economic growth on the electricity consumption: empirical evidence from 67 countries," Journal of the Knowledge Economy, vol. 8, pp. 1-15, 2017.

[15] F. Faisal, T. Tursoy, and N. Berk, "Linear and non-linear impact of internet usage and financial deepening on electricity consumption for Turkey: empirical evidence from asymmetric causality," Environmental Science and Pollution Research International, vol. 4, pp. 1-20, 2018.

[16] M. N. I. Afzal, J. Gow, and A. Rahman, "Economic and internet growth effect on electricity consumption in the BRICS countries," International Advances in Economic Research, vol. 25, no. 3, pp. 339-346, 2019.

[17] Y. Cho, J. Lee, and T.-Y. Kim, “The impact of ICT investment and energy price on industrial electricity demand: dynamic growth model approach," Energy Policy, vol. 35, no. 9, pp. 4730-4738, 2007.

[18] Y. Kishita, Y. Yamaguchi, Y. Umeda et al., "Describing longterm electricity demand scenarios in the telecommunications industry: a case study of Japan," Sustainability, vol. 8, no. 1, pp. 52-16, 2016.

[19] M. Salahuddin and K. Alam, "Information and communication technology, electricity consumption and economic growth in OECD countries: a panel data analysis," International Journal of Electrical Power \& Energy Systems, vol. 76, pp. 185-193, 2016.

[20] S. Sassi and M. Goaied, "Financial development, ICT diffusion and economic growth: lessons from MENA region," Telecommunications Policy, vol. 37, no. 4-5, pp. 252-261, 2013.

[21] Z. Latif, Y. mengke, L. Danish et al., "The dynamics of ICT, foreign direct investment, globalization and economic growth: panel estimation robust to heterogeneity and crosssectional dependence," Telematics and Informatics, vol. 35, no. 2, pp. 318-328, 2018.

[22] A. Das, M. Chowdhury, and S. Seaborn, "ICT diffusion, financial development and economic growth: new evidence from low and lower middle-income countries," Journal of the Knowledge Economy, vol. 9, no. 3, pp. 928-947, 2018.

[23] G. G. Haftu, "Information communications technology and economic growth in Sub-Saharan Africa: a panel data 
approach," Telecommunications Policy, vol. 43, no. 1, pp. 88-99, 2019.

[24] C. Cheng, M. Chien, and C. Lee, "ICT diffusion financial development and economic growth an international cross country analysis," Economic Modelling, vol. 94, pp. 662-671, 2020.

[25] S. Asongu and N. M. Odhiambo, "Foreign direct investment, information technology and economic growth dynamics in Sub-Saharan Africa," Telecommunications Policy, vol. 44, Article ID 101838, 2020.

[26] M. Cardona, T. Kretschmer, and T. Strobel, "ICT and productivity: conclusions from the empirical literature," Information Economics and Policy, vol. 25, no. 3, pp. 109-125, 2013.

[27] K. Vu, P. Hanafizadeh, and E. Bohlin, "ICT as a driver of economic growth: a survey of the literature and directions for future research," Telecommunications Policy, vol. 44, no. 2, Article ID 101922, 2020.

[28] H. Hamdi, R. Sbia, and M. Shahbaz, "The nexus between electricity consumption and economic growth in Bahrain," Economic Modelling, vol. 38, pp. 227-237, 2014.

[29] J. E. Payne, "A survey of the electricity consumption-growth literature," Applied Energy, vol. 87, no. 3, pp. 723-731, 2010.

[30] I. M. Ouédraogo, "Electricity consumption and economic growth in Burkina Faso: a cointegration analysis," Energy Economics, vol. 32, no. 3, pp. 524-531, 2010.

[31] S.-H. Yoo and S.-Y. Kwak, "Electricity consumption and economic growth in seven south American countries," Energy Policy, vol. 38, no. 1, pp. 181-188, 2010.

[32] M. Shahbaz, C. F. Tang, and M. Shahbaz Shabbir, "Electricity consumption and economic growth nexus in Portugal using cointegration and causality approaches," Energy Policy, vol. 39, no. 6, pp. 3529-3536, 2011.

[33] R. Sbia, M. Shahbaz, and I. Ozturk, "Economic growth, financial development, urbanisation and electricity consumption nexus in UAE," Economic Research-Ekonomska Istraživanja, vol. 30, no. 1, pp. 527-549, 2017.

[34] J. Wang, J. Zhao, and H. Li, "The electricity consumption and economic growth nexus in China: a bootstrap seemingly unrelated regression estimator approach," Computational Economics, vol. 52, no. 4, pp. 1195-1211, 2018.

[35] R. P. Pradhan, M. B. Arvin, and N. R. Norman, "The dynamics of information and communications technologies infrastructure, economic growth, and financial development: evidence from Asian countries," Technology in Society, vol. 42, pp. 135-149, 2015.

[36] M. Osman, G. Gachino, and A. Hoque, "Electricity consumption and economic growth in the GCC countries: panel data analysis," Energy Policy, vol. 98, pp. 318-327, 2016.

[37] N. Apergis and J. E. Payne, "The electricity consumptiongrowth nexus: renewable versus non-renewable electricity in Central America," Energy Sources, vol. 7, no. 1-4, pp. 423-431, 2012.

[38] Y. Wolde-Rufael, "Electricity consumption and economic growth in transition countries: a revisit using bootstrap panel granger causality analysis," Energy Economics, vol. 44, pp. 325-330, 2014.

[39] W.-C. Lu, "Electricity consumption and economic growth: evidence from 17 Taiwanese industries," Sustainability, vol. 9, no. 1, p. 50, 2017.

[40] L. G. Brookes, "Energy efficiency and economic fallacies: a reply,” Energy Policy, vol. 20, no. 5, pp. 390-392, 1992.

[41] B. Lin and H. Zhao, "Technological progress and energy rebound effect in China's textile industry: evidence and policy implications," Renewable and Sustainable Energy Reviews, vol. 60, pp. 173-181, 2016.

[42] Y. Li, L. Sun, T. Feng, and C. Zhu, "How to reduce energy intensity in China: a regional comparison perspective," Energy Policy, vol. 61, pp. 513-522, 2013.

[43] J. Yin, S. Wang, and L. Gong, "The effects of factor market distortion and technical innovation on China's electricity consumption," Journal of Cleaner Production, vol. 188, pp. 195-202, 2018.

[44] H. An, J. Xu, and X. Ma, "Does technological progress and industrial structure reduce electricity consumption? Evidence from spatial and heterogeneity analysis," Structural Change and Economic Dynamics, vol. 52, pp. 206-220, 2020.

[45] J. P. Elhorst, Spatial Econometrics: From Cross-Sectional Data to Spatial Panels, Springer, Heidelberg, Germany, 2014.

[46] L. Anselin, Spatial Econometrics: Methods and Models, Kluwer Academic Publishers, Dordrecht, NL, USA, 1998.

[47] R. M. Baron and D. A. Kenny, "The moderator-mediator variable distinction in social psychological research: conceptual, strategic, and statistical considerations," Journal of Personality and Social Psychology, vol. 51, no. 6, pp. 11731182, 1986.

[48] B. Li, S. Shi, and Y. Zeng, "The impact of haze pollution on firm-level TFP in China: test of a mediation model of labor productivity," Sustainability, vol. 12, no. 20, pp. 1-21, 2020.

[49] Y. Xu, X. Fan, Z. Zhang, and R. Zhang, “Trade liberalization and haze pollution: evidence from China," Ecological Indicators, vol. 109, no. 2, pp. 1-13, 2020.

[50] M. H. Pesaran, "General diagnostic tests for cross section dependence in panels," Cambridge Working Papers in Economics, No. 0435, 2004, http://www.econ.cam.ac.uk/ research-files/repec/cam/pdf/cwpe0435.pdf.

[51] B. H. Baltagi, Q. Feng, and C. Kao, "A Lagrange multiplier test for cross-sectional dependence in a fixed effects panel data model," Journal of Econometrics, vol. 170, no. 1, pp. 164-177, 2012.

[52] J. P. Elhorst, "Matlab software for spatial panels," International Regional Science Review, vol. 37, no. 3, pp. 389-405, 2014.

[53] L.-F. Lee and J. Yu, "Estimation of spatial autoregressive panel data models with fixed effects," Journal of Econometrics, vol. 154, no. 2, pp. 165-185, 2010.

[54] J. P. Elhorst, "Specification and estimation of spatial panel data models," International Regional Science Review, vol. 26, no. 3, pp. 244-268, 2016.

[55] J. P. LeSage and R. K. Pace, Introduction to Spatial Econometrics, CRC Press, New York, NY, USA, 2009.

[56] C. Bao and R. Liu, "Electricity consumption changes across China's provinces using a spatial shift-share decomposition model," Sustainability, vol. 11, no. 9, pp. 2494-2515, 2019.

[57] S. Liu and H. Li, "Does financial development increase urban electricity consumption? Evidence from spatial and heterogeneity analysis," Sustainability, vol. 12, no. 17, pp. 7011-7017, 2020.

[58] M. Bouznit, M. Pablo-Romero, and A. Sánchez-Braza, "Residential electricity consumption and economic growth in Algeria," Energies, vol. 11, no. 7, pp. 1656-1717, 2018.

[59] Y. Han, J. Shi, Y. Yang, and Y. Wang, "Direct rebound effect for electricity consumption of urban residents in China based on the spatial spillover effect," Energies, vol. 12, no. 11, pp. 1-16, 2019.

[60] P. C. Bosah, S. Li, G. K. M. Ampofo, D. A. Asante, and Z. Wang, "The nexus between electricity consumption, economic growth, and $\mathrm{CO}_{2}$ emission: an asymmetric analysis 
using nonlinear ARDL and nonparametric causality approach," Energies, vol. 13, no. 5, pp. 1-24, 2020.

[61] S. A. Solarin, M. Shahbaz, H. N. Khan, and R. B. Razali, "ICT, financial development, economic growth and electricity consumption: new evidence from Malaysia," Global Business Review, vol. 17, no. 6, pp. 1480-1496, 2019.

[62] X. Liu, L. Yu, Y. Zhang, and Y. Chao, "Spatial spillover effect of financial flexibility on investment in China's convention and exhibition listed companies," Mathematical Problems in Engineering, vol. 2020, Article ID 3926747, 10 pages, 2020.

[63] X. Yu, M. Shen, W. Shen, and X. Zhang, "Effects of land urbanization on smog pollution in China: estimation of spatial autoregressive panel data models," Land, vol. 9, no. 9, pp. 1-16, 2020.

[64] J. A. Hausman, "Specification tests in econometrics," Econometrica, vol. 46, no. 6, pp. 1251-1271, 1978.

[65] A. A. Rafindadi and I. Ozturk, "Effects of financial development, economic growth and trade on electricity consumption: evidence from Post-Fukushima Japan," Renewable and Sustainable Energy Reviews, vol. 54, pp. 1073-1084, 2016.

[66] X. Liu, T. Sun, Q. Feng, and D. Zhang, "Dynamic nonlinear influence of urbanization on China's electricity consumption: evidence from dynamic economic growth threshold effect," Energy, vol. 196, no. 4, pp. 1-11, 2020. 